\title{
Promoting Public Engagement of Natural History Collections through Science Communication
}

\author{
Bryan Lessard $¥$ \\ ‡ Australian National Insect Collection, CSIRO, Canberra, Australia
}

Corresponding author: Bryan Lessard (bryan.lessard@csiro.au)

Received: 19 Jul 2018 | Published: 25 Jul 2018

Citation: Lessard B (2018) Promoting Public Engagement of Natural History Collections through Science

Communication. Biodiversity Information Science and Standards 2: e28479. https://doi.org/10.3897/biss.2.28479

\begin{abstract}
Natural history collections are essential for understanding the world's biodiversity and drive research in taxonomy, systematics, ecology and biosecurity. One of the biggest challenges faced is the decline of new taxonomists and public interest in collections-based research, which is alarming considering that an estimated $70 \%$ of the world's species are yet to be formally described.

Science communication combines public relations with the dissemination of scientific knowledge and offers many benefits to promoting natural history collections to a wide audience. For example, social media has revolutionised the way collections and their staff communicate with the public in real time, and can attract more visitors to collection exhibits and new students interested in natural history. Although not everyone is born a natural science communicator, institutions can encourage and provide training for their staff to become engaging spokespeople skilled in social media and public speaking, including television, radio and/or print media. By embracing science communication, natural history collections can influence their target audiences in a positive and meaningful way, raise the profile of their institution, encourage respect for biodiversity, promote their events and research outputs, seek philanthropic donations, connect with other researchers or industry leaders, and most importantly, inspire the next generation of natural historians.
\end{abstract}




\section{Keywords}

biodiversity, taxonomy, systematics, ecology, science communications, science engagement

\section{Presenting author}

Dr Bryan Lessard, Australian National Insect Collection, CSIRO

\section{Presented at}

SPNHC-TDWG.2018 